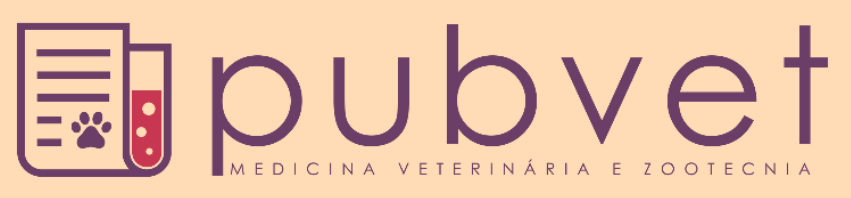

https://doi.org/10.31533/pubvet.v15n12a979.1-8

\title{
Samburá: $O$ alimento fermentado das abelhas sem ferrão na sua mesa
}

\author{
Jonival Santos Nascimento Mendonça Neto ${ }^{1 *} \bullet$, Ney Tiago Bezerra Xavier ${ }^{\bullet}$, Adcléia Pereira \\ Pires $^{2}{ }^{\circ}$, Brena Peleja Vinholte ${ }^{3} \bullet$, Andria Tavares Galvão ${ }^{4}{ }^{\circ}$ \\ ${ }^{I}$ Acadêmico do Curso de Medicina veterinária, Universidade da Amazônia - Unama. Santarém-PA. Brasil. \\ ${ }^{2}$ Mestranda em Ciências Ambientais, Instituto de Engenhariae Geociências, Programade Pós-graduação em Recursos NaturaisdaAmazônia, Universidade Federal do Oeste do Pará. \\ ${ }^{3}$ Professora da Universidade da Amazônia, Departamento de Medicina Veterinária. Santarém - PA, Brasil. \\ ${ }^{4}$ Graduada em Zootecnia, Universidade Federal do Oeste do Pará, Santarém, Pará. \\ *Autor para correspondência, E-mail: jonivalmendonca@gmail.com
}

Resumo. As abelhas sem ferrão estocam os alimentos de interesse como: mel e samburá, uma estratégia que as abelhas utilizam para aproveitar as épocas de florada, disponibilidade do néctar e pólen, e assim é possível garantir alimentos para toda a colônia, permitindo a produção, reprodução e sobrevivência das colônias em períodos de escassez. As informações sobre a composição, qualidade e consumo do samburá ainda são poucas comparadas ao pólen de Apis mellífera. Desta forma, o objetivo deste estudo foi realizar uma pesquisa dos estudos relacionados às propriedades físico-química e biológicas do samburá, produto das abelhas sem ferrão. A metodologia dotada para realizar a revisão baseou-se em busca de publicações em: E-Books Backlist, capítulos de livro, artigos científicos. A pesquisa foi realizada com base nos dados da Web of Science, Science Direct, Scientific Electronic Library Online, Google Acadêmico e PubMed, assim como em rede social voltada à pesquisa como a Research Gate e sites de vendas do produto. Foram utilizados como palavras-chave: samburá, pão proteico de abelhas, pão-de-abelhas, pólen, pólen armazenado, pólen de abelhas, pólen de abelhas sem ferrão, potes de pólen e produtos da colônia de abelhas nativas. O samburá, pólen de pote ainda não possui uma regulamentação e muito menos a padronização estabelecida pelo Ministério da Agricultura e pecuária - MAPA, sendo um produto comercializado de forma direta, geralmente do meliponicultor ao consumidor e hoje em redes sociais e sites de vendas de algumas empresas da cadeia da meliponicultora. Assim, são necessárias mais pesquisas de sua caracterização por biomas e regiões geográficas, estímulo de políticas públicas para legalizar o produto. As características químicas do samburá favorecem à saúde e bem-estar quando usados continuamente, com alto potencial biológico, atividades antioxidantes, mas ressaltando que ainda necessita de regulamento técnico.

Palavras-chave: Pólen, proteínas, segurança alimentar, suplemento alimentar

\section{Samburá: The fermented food of stingless bees on your table}

Abstract. Stingless bees' stock the foods of interest such as honey and samburá, a strategy that bees use to take advantage of flowering times, availability of nectar and pollen, and thus it is possible to guarantee food for the entire colony, allowing production and reproduction and survival of colonies in periods of scarcity. Information on composition, quality and consumption of samburá is still limited compared to Apis mellifera pollen. Thus, the aim of this study was to carry out a search for studies related to physicochemical and biological properties of samburá, a product of stingless bees. The methodology used to carry out the review was based on the search for publications in: E-Books Backlist, book chapters, scientific articles. The research was conducted in databases from the Web of Science, Science Direct, Scientific Electronic Library Online, Academic Google and 
PubMed, as well as in a social network dedicated to research such as ResearchGate and product sales sites. Keywords were used as: samburá, bee protein bread, bee bread, pollen, stored pollen, bee pollen, stingless bee pollen, pollen pots and native bee colony products. The samburá, pot pollen still does not have regulation, much less the standardization established by the Ministry of Agriculture and Livestock - MAPA, being a product sold directly, generally from the beekeeper to the consumer and today through social networks and sales sites of some companies in the meliponiculture chain, and further research is needed on its characterization by biomes and geographic regions, and encouragement of public policies to legalize the product. The chemical characteristics of samburá favor health and well-being when used continuously, with high biological potential, antioxidant activities, but noting that it still needs technical regulation.

Keywords: Pollen, proteins, food safety, food supplement

\section{Introdução}

As abelhas sem ferrão estocam os alimentos de interesse para sua saúde que mantenha sua colônia saudável para fins de produção e reprodução. os produtos são: mel, própolis e samburá. Essa é uma estratégia que as abelhas utilizam para aproveitar as épocas de florada, disponibilidade do néctar e pólen, e assim é possível garantir alimentos para toda a colônia em períodos de escassez.

O samburá é o pólen armazenado em potes de cerume construído pelas abelhas sem ferrão para estocagem de alimentos, conhecido como "pólen de pote" é um produto fermentado, rico em nutrientes, oriundo da meliponicultura, atividade tradicional e milenar que consiste na criação racional de abelhas sem ferrão, atividade econômica e sustentável (Francisco et al., 2016). A difusão do conhecimento de suas propriedades, do valor nutritivo, dos benefícios adquiridos com sua ingestão pode promover o mercado e o desenvolvimento da cadeia produtiva, contribuindo para a conservação das espécies de abelhas e da preservação dos biomas em que a meliponicultura está presente. O samburá é um alimento fermentado rico em proteínas, com 22 aminoácidos, produzido pelas abelhas sem ferrão, o qual as abelhas coletam o pólen das flores e a partir de reações físico-química e biológica transformam no samburá, o pão de abelha. Este alimento possui na sua composição compostos bioativos, minerais, ácidos graxos, proteínas, aminoácidos essenciais e fibras (Campos et al., 2010; Nogueira Neto, 1997).

Localização geográfica, condições edafoclimáticas e fontes botânicas são responsáveis pela qualidade físico-química e biológica do samburá; além das boas práticas do manipulador serem responsáveis pelas condições microbiológicas (Campos et al., 2010; Nogueira Neto, 1997). De acordo com Denisow \& Denisow-Pietrzyk (2016) o pólen é um alimento estocado pelas abelhas com alto valor nutritivo e funcional; com potencial fármaco, alimentar e industrial (Bárbara et al., 2015). As informações sobre o pólen coletado pelas abelhas sem ferrão, ainda são poucas difundidas, devido às diversidades das espécies das abelhas e da vegetação, clima e solo dos ecossistemas distribuídos no Brasil e mundo. Desta forma, sua comercialização ainda é informal.

O objetivo deste estudo foi de realizar uma pesquisa dos estudos relacionados às propriedades físicoquímica e biológicas do samburá, produto das abelhas sem ferrão.

\section{Metodologia}

O trabalho baseou-se em pesquisa de publicações em: E-Books Backlist, capítulos de livro, artigos científicos. A pesquisa foi realizada em base de dados da Web of Science, Science Direct, Scientific Electronic Library Online, Google Acadêmico e PubMed, assim como em rede social voltada a pesquisa como a Research Gate e sites de vendas do produto. Foram utilizados como palavras-chave os termos samburá, pão proteico de abelhas, pão-de-abelhas, pólen, pólen armazenado, pólen de abelhas, pólen de abelhas sem ferrão, potes de pólen e produtos da colônia de abelhas nativas.

\section{O que é pólen?}

De acordo com Popova et al. (2007), o pólen é o gameta masculino das flores, produzido e armazenado no interior das anteras, o qual é transferido para o ovário, onde ocorre a fecundação, garantindo assim a perpetuação das espécies. O pólen apícola é resultado da colheita dos grãos de pólen 
realizado pelas abelhas Apis mellífera de diferentes fontes florísticas. Este passam por transformações físico-química e no final do armazenamento por desidratação (Carpes et al., 2009; Nogueira Neto, 1997). O pólen coletado pelas abelhas sem ferrão, após sofrer reações físico-química, é denominado de samburá. Este material armazenado pelas abelhas sociais sem ferrão em potes construídos de cerume que passam por transformações físico-química e biológica (Alves \& Santos, 2018; Nogueira Neto, 1997).

\section{Samburá, o que é?}

As abelhas visitam as flores para a coleta do pólen de acordo com suas necessidades nutricionais. Durante a visitação de flor em flor, o pólen fica grudado nos pêlos do corpo das abelhas no momento do contato com os estames. Após a coleta são escovados com os pentes tibiais. O pólen é transportado para o interior da colônia, onde as abelhas adicionam mel e enzimas digestivas para posterior armazenamento nos potes de cerume. Estes passam por transformações físico-químicas após o fechamento dos potes, iniciando a fermentação láctica. A fermentação pode durar de duas a quatro semanas, com objetivo de conservação do samburá (Figura 1). As enzimas salivares digerem os grânulos de pólen floral tornando os seus nutrientes bio-disponíveis para alimentação das larvas (Estevinho et al., 2012; Vásquez \& Olofsson, 2009).

O pólen coletado pelas abelhas sem ferrão é depositado nos potes de cerume com adição de enzimas e néctar (Figura 1), os quais apresentam várias cores, que variam de acordo com a coleta e também com o tempo de armazenamento. Após a realização da coleta do pólen, os potes são fechados para a fermentação natural. As cores variam do amarelo ao marrom, $\mathrm{pH}$ em torno de 2,6 com baixo número de microrganismos, alimento rico em proteínas para o consumo das abelhas (Silva \& Zucoloto, 1994). Após uns sete dias de armazenamento, o pólen no pote de cerume torna-se uma massa fermentada, com alterações em suas características sensoriais (odor, sabor, cor e textura) (Souza et al., 2021). Menezes et al. (2013) afirmam que existe uma variação nas características entre as espécies de abelhas, inclusive na comparação do samburá da espécie da Tetragonisca angustula e constataram um produto mais doce e seco, enquanto no gênero da Scaptotrigona, mais úmido e ácido. Uma percepção relevante é a característica sensorial do samburá da espécie produzida pelo gênero da Friseomelitta (Figura 2) com sabor mais adocicado e bem mais seco que os demais. Além disso, essa espécie coleta pólen de outras espécies quando disponíveis.

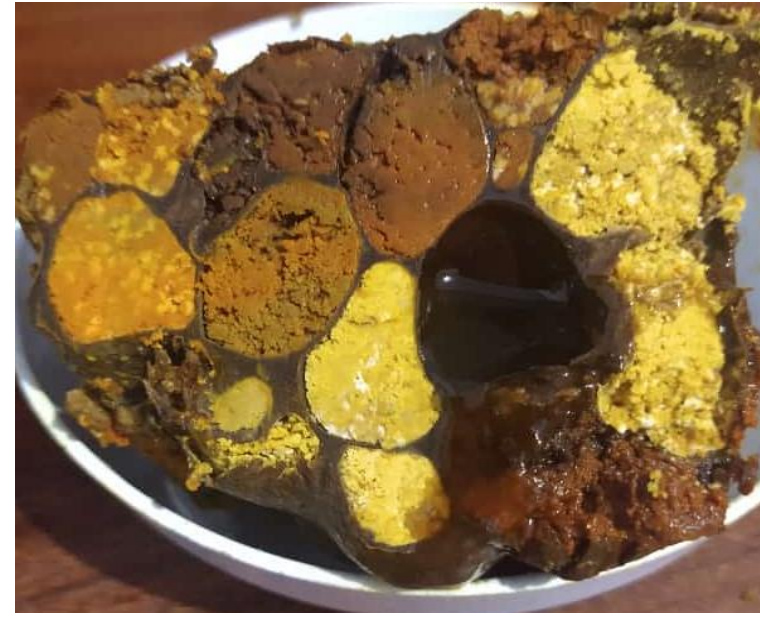

Figura 1. Pote de pólen de abelhas sem ferrão nativas do Oeste do Pará.

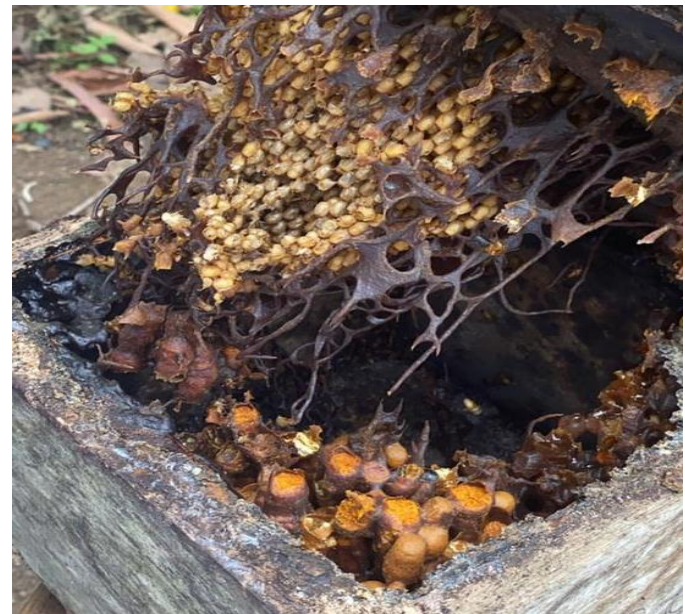

Figura 2. Pote de pólen da abelha Friseomelitta longipes.

Vásquez \& Olofsson (2009) afirmaram que os principais microrganismos responsáveis pela fermentação láctica são os Streptococcus, Bifidobacterium e Lactobacillus. As leveduras também têm um aumento considerável, onde as mesmas podem fazer parte da fermentação do pólen. A conservação do pólen tem uma relação com a acidez; pois, inibe o crescimento de alguns microrganismos, o que não se verifica na conservação do pólen apícola, que requer uma secagem logo após a coleta para evitar a sua degradação. 
O pólen de pote (samburá) do gênero Meliponas de três espécies do Estado do Amazonas foi estudado sua composição nutricional o qual avaliou o teor de proteínas que apresentou uma variação de $15,7 \%$ a 23,0\%, lipídeos de 1,9 a 9,3\% e glicídios de 26,4\% a 57,4\% (Galvão et al., 2019). Seguindo os estudos da composição do samburá, se dá por flavonoides (narigerina, tricetina, isohraminetina e 8metoxiherbacetina), presença de açucares e aminoácidos (Silva et al., 2014).

A fermentação do pólen de abelhas nativas é um processo natural que tem a função de conservação do "pão de abelha", o alimento proteico das abelhas sociais sem ferrão. A necessidade de armazenar, estocar alimento para período de escassez fez com que estratégias fossem dotadas para sua conservação e seu uso posterior. Além disso, estas transformações são necessárias para deixar o pólen biodisponível, facilitando a absorção de nutrientes pelas abelhas.

Conforme observado na tabela 1 , há uma diferença na composição de nutrientes no samburá coletado no mesmo meliponário. Todavia, em espécies diferentes, salienta-se que a maior influência é origem da composição florística, e por outro lado, as abelhas buscam o sítio florístico de acordo com a necessidade da colônia. A tabela 1 também revela a riqueza dos nutrientes do samburá quanto ao teor de lipídeos, carboidratos e proteínas, corroborando para os estudos com o seu potencial promissor para a alimentação humana.

Tabela 1. Composição Centesimal de samburá de abelhas nativas do Rios Arapiuns, Pará.

\begin{tabular}{lccc}
\hline Abelha sem ferrão & Lipídeos $(\mathrm{g} / 100 \mathrm{~g})$ & Carboidratos $(\mathrm{g} / 100 \mathrm{~g})$ & Proteínas $(\mathrm{g} / 100 \mathrm{~g})$ \\
\hline Melipona sp. & 1,44 & 17,36 & 28,63 \\
Melipona interrupta & 15,81 & 26,75 & 22,17 \\
Scaptotrigona polysticta & 10,54 & 50,28 & 12,39 \\
\hline
\end{tabular}

Adaptada de Galvão et al. (2019).

O samburá é indispensável para a qualidade de vida da colônia e sua sanidade. Os teores de lipídeos, carboidratos e proteínas (Tabela 1) são fundamentais na dieta e não é possível o desenvolvimento saudável das abelhas sem este alimento. Ainda, tais nutrientes são importantes para dieta humana, como fonte de energia e proteína.

\section{Samburá, alimento funcional}

A atribuição ao pólen de possuir propriedades terapêuticas vem desde a antiguidade. O conhecimento empírico proporcionou seu uso na medicina tradicional em tratamentos de resfriados, gripes, úlceras, envelhecimento precoce, anemia, colite, alergias, enterite e outras doenças (Campos et al., 2010; $\underline{\text { Pascoal }}$ et al., 2014).

O mercado para o samburá está crescendo, potencializando assim mais um produto da meliponicultura, sendo possível encontrar o samburá de abelhas sem ferrão comercializado puro e desidratado ou como um composto misturado ao mel, reduzindo, assim, sua acidez (Souza et al., 2020). Cada vez mais os alimentos naturais, saudáveis, funcionais estão ganhando mercado (Cândido \& Campos, 2005). O consumidor está procurando os benefícios proporcionados pelos alimentos naturais. Baseado neste contexto, o pólen tem sido um produto oriundo da apicultura que vem ganhando mercado (Carpes et al., 2009). Consumidores conscientes de sua composição rica em aminoácidos essenciais, proteínas, vitaminas, minerais e outros que são totalmente benéficas à saúde humana estimulam sua produção (Alves \& Santos, 2018; Barreto et al., 2006). O pólen é um alimento com características nutritivas, possui propriedades biológica, responsável por ações específicas e benéficas ao organismo humano (Carpes et al., 2009). O pólen é um alimento funcional (Ramalho et al., 2007; Silva et al., 2014), por possuir atividade antifúngica, antiinflamatória, imunomoduladora, anti-cariogênica e antibacteriana, exerce ainda função antioxidante, que inibi a ação lesiva dos radicais livres (Graikou et al., 2011).

A composição do pólen de pote armazenado possui maior quantidade e qualidade de nutrientes do que o pólen das flores antes da colheita; pois, as abelhas acrescentam secreções salivares com suas enzimas, adicionam o néctar, assim enriquecendo o produto final com nutrientes que o permitem ser um alimento funcional com atividades biológicas e maior proporção nutricional comparado ao pólen das flores (Chantarudee et al., 2012). Portanto, baseado nisso apresenta-se como um alimento natural, devido sua composição química com alto teor de compostos fenólicos em especial flavonoides e polifenóis que 
conferem atividades antioxidantes, sendo um verdadeiro suplemento alimentar com funções terapêuticas e nutricionais (Denisow \& Denisow-Pietrzyk, 2016). Suas propriedades impulsionam seu consumo (Freire et al., 2012).

As propriedades benéficas atribuídas ao consumo do pólen devido sua composição química impulsiona seu consumo, seu uso diário é capaz de combate os radicais livres, além de serem agentes antibacterianos (Isidorov et al., 2015), antioxidantes naturais (Florio Almeida et al., 2017) e de atuarem como quimio-preventivos (Omar et al., 2016). Dada toda sua importância nutricional, o pólen de pote (samburá) e os benefícios comprovados pelos estudos voltados para sua composição química e biológica, por diferentes espécies de abelhas, pesquisas vêm sendo realizadas sobre a composição química e bioatividades do pólen armazenado por abelhas sem ferrão (Rebelo et al., 2016; Vit et al., $\underline{2016}$.

\section{Composição físico-química do samburá}

As condições ambientais, edafoclimáticas, origem das fontes botânicas, a idade e estado nutricional das plantas e a sazonalidade são fatores que influenciam na composição físico-química do samburá. Diferentes estudos abordam que o pólen é o produto da colmeia que possui maior diversidade (Carpes et al., 2009; Eswaran \& Bhargava, 2014; Nogueira Neto, 1997), e com isso o conhecimento a respeito das características físico-químico e biológicas se tornam relevante no sentido de caracterizar o produto obtido em diferentes regiões e controlar a qualidade, agregando valor comercial ao produto (Marchini et al., 2001; Sodré et al., 2011; Sodré et al., 2007).

O samburá e o pólen coletados e armazenados nas colônias pelas abelhas sociais sem ferrão, têm pouco material divulgado. Ainda, não tem uma legislação e uma padronização que promova sua comercialização formal. Na tentativa de contribuir na elaboração de uma legislação apropriada para o pólen coletado por abelhas sem ferrão, diversos pesquisadores buscaram caracterizar o samburá de diferentes espécies de abelhas sem ferrão (Alves \& Santos, 2018; Bárbara et al., 2015).

Em análises de compostos fenólicos do samburá das espécies de abelhas do gênero Melipona e Scaptotrigona coletado em período chuvoso na região do rio Arapiuns na Amazônia foram encontrados resultados médios de 18,53 $\pm 0,14$ a 5,31 $\pm 0,27 \mu \mathrm{mol}$ EAG/mg. Quanto aos teores de flavonoides, as amostras apresentaram valores entre 12,38 $\pm 2,73$ e $0,73 \pm 0,12 \mu \mathrm{mol}$ ERT/mg, com maiores teores para Melipona. Na mesma pesquisa foi revelado a capacidade antioxidante do samburá, com melhores resultados para espécie Scaptotrigona spp. e do potencial terapêutico e nutricional do produto por causa dos compostos bioativos presente (Vit et al., 2016). De acordo com Bárbara et al. (2015), após realizar análises de samburá da espécie Melipona spp. de diferentes regiões do Brasil, observaram maior segurança alimentar do produto para consumo do ponto de vista microbiológico e nutricional. Alves et al. (2018) reafirmaram, após análise química do samburá da espécie Melipona scutellaris, uma diferença do pólen armazenado em pote, o qual é fermentado. Bárbara et al. (2018) verificaram diferenças físicoquímicas existentes em samburás armazenados por diferentes espécies de abelhas sociais sem ferrão do Nordeste do Brasil. Assim como Galvão et al. (2019) confirmaram a diferença na composição centesimal após realizar análises de umidade, cinzas, proteínas, lipídeos e carboidratos no samburá de três diferentes espécies de abelhas coletados no mesmo período e local.

Estudo realizado por Alves et al. (2018) com amostras de samburá do interior da Bahia, observou-se os seguintes valores médios: $44,71 \%$ de umidade, $1,84 \%$ de cinzas, $4,25 \%$ de lipídios, $23,88 \%$ de proteínas, $0,87 \%$ de fibras, $24,48 \%$ de carboidratos, $\mathrm{pH} 3,75$, uma acidez livre de 150,57 meq/100 kg, uma atividade de água de 0,92 e um valor de energia total de $231,33 \mathrm{kcal} / 100 \mathrm{~g}$. Além disso, as análises microbiológicas revelaram que o produto era satisfatório e estava livre de patógenos.

Santos et al. (2019) analisando amostras de samburá de seis espécies de abelhas nativas de três ecossistemas distintos, uma em área de várzea, alagada, a segunda em uma área de Rios de água doce com floresta primária e culturas plantadas e a terceira uma área de terra firme com plantio de sistema agroflorestal em regiões de Santarém e Belterra do Oeste do Pará, constataram diferenças significativas nos compostos fenólicos totais, inclusive relataram menores concentrações no samburá de cor clara da área da várzea, afirmando resultados superiores nas amostras do assentamento agroextrativista e do sistema agroflorestal. 


\section{Considerações finais}

O samburá, pólen de pote ainda não possui uma regulamentação e muito menos a padronização estabelecida pelo Ministério da Agricultura e pecuária, sendo um produto comercializado de forma direta, geralmente do meliponicultor ao consumidor e hoje pelas redes sociais e sites de vendas de algumas empresas da cadeia da meliponicultura. Desta forma, são necessárias mais pesquisas de caracterização, estímulo de políticas públicas para legalização do produto. As características químicas do samburá favorecem a saúde e bem-estar quando usados continuamente, com alto potencial biológico, mas ressaltando que ainda necessita de regulamentação técnica.

\section{Referências bibliográfica}

Alves, R. F., \& Santos, F. A. R. (2018). Análise volumétrica do pólen de Attalea funifera Mart.(Arecaceae) em amostras de pólen apícola do litoral do baixo sul da Bahia, Brasil. Paubrasilia, 1(2), 5-11. https://doi.org/10.33447/paubrasilia.v1i2.14.

Bárbara, M. S., Machado, C. S., Sodré, G. S., Dias, L. G., Estevinho, L. M., \& Carvalho, C. A. L. (2015). Microbiological assessment, nutritional characterization and phenolic compounds of bee pollen from Mellipona mandacaia Smith, 1983. Molecules, 20(7), 12525-12544. https://doi.org/10.3390/molecules200712525.

Barreto, L., Funari, S. R. C., Orsi, R. O., \& Dib, A. P. S. (2006). Produção de pólen no Brasil. Cabral Editora e Livraria Universitária.

Campos, M. G. R., Frigerio, C., Lopes, J., \& Bogdanov, S. (2010). What is the future of Bee-Pollen? Journal of ApiProduct and ApiMedical Science, 2(4), 131-144.

Cândido, L. M. B., \& Campos, A. M. (2005). Alimentos funcionais. Uma revisão. Boletim Da Sociedade Brasileira de Ciência e Tecnologia, 29(2), 193-203.

Carpes, S. T., Mourão, G. B., Alencar, S. M., \& Masson, M. L. (2009). Chemical composition and free radical scavenging activity of Apis mellifera bee pollen from Southern Brazil. Brazilian Journal of Food Technology, 12(1/4), 220-229. https://doi.org/10.4260/bjft2009800900016.

Chantarudee, A., Phuwapraisirisan, P., Kimura, K., Okuyama, M., Mori, H., Kimura, A., \& Chanchao, C. (2012). Chemical constituents and free radical scavenging activity of corn pollen collected from Apis mellifera hives compared to floral corn pollen at Nan, Thailand. BMC Complementary and Alternative Medicine, 12(1), 1-12. https://doi.org/10.1186/1472-6882-12-45.

Denisow, B., \& Denisow-Pietrzyk, M. (2016). Biological and therapeutic properties of bee pollen: a review. Journal of the Science of Food and Agriculture, 96(13), 4303-4309. https://doi.org/10.1002/jsfa.7729.

Estevinho, L. M., Rodrigues, S., Pereira, A. P., \& Feás, X. (2012). Pólen de abelha português: estudo palinológico, avaliação nutricional e microbiológica. International Journal of Food Science \& Technology, 47(2), 429-435.

Eswaran, V. U., \& Bhargava, H. R. (2014). Chemical analysis and anti-microbial activity of Karnataka bee bread of Apis species. World Applied Sciences Journal, 32(3), 379-385. https://doi.org/10.5829/idosi.wasj.2014.32.03.1006.

Florio Almeida, J., Reis, A. S., Heldt, L. F. S., Pereira, D., Bianchin, M., de Moura, C., Plata-Oviedo, M. V., Haminiuk, C. W. I., Ribeiro, I. S., \& Luz, C. F. P. (2017). Lyophilized bee pollen extract: A natural antioxidant source to prevent lipid oxidation in refrigerated sausages. LWT-Food Science and Technology, 76, 299-305. https://doi.org/10.1016/j.lwt.2016.06.017.

Francisco, R. S., Correia, F. C. S., Peruquetti, R. C., \& Araújo, C. N. (2016). Dez anos de pesquisas sobre a integração quintais agroflorestais e meliponicultura. Ciência Animal, 26(2), 13-26.

Freire, K. R. L., Lins, A., Dórea, M. C., Santos, F. A. R., Camara, C. A., \& Silva, T. (2012). Palynological origin, phenolic content, and antioxidant properties of honeybee-collected pollen from Bahia, Brazil. Molecules, 17(2), 1652-1664. https://doi.org/10.3390/molecules17021652.

Galvão, A. T., Santos, A., Moreira, D. K. T., Pires, A. P., \& Pacheco, A. (2019). Composição centesimal do pólen de abelhas nativas da comunidade Coroca-Rio Arapiuns, Santarém-Pará. Anais Do III Congresso de Tecnologias e Desenvolvimento Na Amazônia, Composição centesimal do pólen de abelhas nativas. 
Graikou, K., Kapeta, S., Aligiannis, N., Sotiroudis, G., Chondrogianni, N., Gonos, E., \& Chinou, I. (2011). Chemical analysis of Greek pollen-Antioxidant, antimicrobial and proteasome activation properties. Chemistry Central Journal, 5(1), 1-9. https://doi.org/10.1186/1752-153X-5-33.

Isidorov, V. A., Bagan, R., Bakier, S., \& Swiecicka, I. (2015). Chemical composition and antimicrobial activity of Polish herbhoneys. Food Chemistry, 171, 84-88. https://doi.org/10.1007/s10600-016-1566-y.

Marchini, L. C., Moreti, A., Teixeira, E. W., Silva, E. C. A., Rodrigues, R. R., \& Souza, V. C. (2001). Plantas visitadas por abelhas africanizadas em duas localidades do estado de São Paulo. Scientia Agricola, 58(2), 413-420.

Menezes, C., Vollet-Neto, A., Contrera, F. A. F. L., Venturier, i G. C., \& Imperatriz-Fonseca, V. L. (2013). O papel de microorganismos úteis para abelhas sem ferrão e apicultura sem ferrão. In P. Vit, S. R. M., \& D. Roubik (Eds.), Pot-Honey: Um legado de abelhas sem ferrão (pp. 153-171). Springer.

Nogueira Neto, P. (1997). Vida e criação de abelhas indígenas sem ferrão. Editora Nogueirapis.

Omar, W. A. W., Azhar, N. A., Fadzilah, N. H., \& Kamal, N. N. S. N. M. (2016). Bee pollen extract of Malaysian stingless bee enhances the effect of cisplatin on breast cancer cell lines. Asian Pacific Journal of Tropical Biomedicine, 6(3), 265-269. https://doi.org/10.1016/j.apjtb.2015.12.011.

Pascoal, A., Rodrigues, S., Teixeira, A., Feás, X., \& Estevinho, L. M. (2014). Biological activities of commercial bee pollens: Antimicrobial, antimutagenic, antioxidant and anti-inflammatory. Food and Chemical Toxicology, 63, 233-239. https://doi.org/10.1016/j.fct.2013.11.010.

Popova, M. P., Bankova, V. S., Bogdanov, S., Tsvetkova, I., Naydenski, C., Marcazzan, G. L., \& Sabatini, A. G. (2007). Chemical characteristics of poplar type propolis of different geographic origin. Apidologie, 38(3), 306-311.

Ramalho, M., Silva, M. D., \& Carvalho, C. A. L. (2007). Dinâmica de uso de fontes de pólen por Melipona scutellaris Latreille (Hymenoptera: Apidae): uma análise comparativa com Apis mellifera L.(Hymenoptera: Apidae), no Domínio Tropical Atlântico. Neotropical Entomology, 36(1), 38-45. https://doi.org/http://dx.doi.org/10.1590/S1519-566X2007000100005.

Rebelo, K. S., Ferreira, A. G., \& Carvalho-Zilse, G. A. (2016). Características físico-químicas do pólen coletado por abelhas amazônicas sem ferrão. Ciência Rural, 46(5), 927-932. https://doi.org/10.1590/0103-8478cr20150999.

Santos, A. S., Galvão, A. T., Pires, A. P., Pacheco, A., Moreira, D. K. T. (2019). Avaliação do teor de compostos fenólicos, flavonoides e capacidade antioxidante do pólen coletado por abelhas sem ferrão. Anais do III Congresso de Tecnologias e Desenvolvimento na Amazônia, 2019.

Silva, G. R., Natividade, T. B., Camara, C. A., Silva, E. M. S., Santos, F. D. A. R., \& Silva, T. M. S. (2014). Identificação de açúcares, aminoácidos e minerais do pólen de abelhas sem ferrão Jandaíra (Melipona subnitida). Food and Nutrition Sciences, 5, 1015.

Silva, P. G. F., \& Zucoloto, F. S. (1994). Influência de microrganismos no valor nutritivo do pólen para Scaptotrigona depilis, Moure (Hymenoptera, Apidae). Anais 1 Encontro Sobre Abelhas Em Ribeirão Preto SP Brazil, 1994, 232-242.

Sodré, G S, Marchini, L. C., Moreti, A. C., Otsuk, I. P., \& Carvalho, C. A. L. (2011). Physico-chemical characteristics of honey produced by Apis mellifera in the Picos region, state of Piauí, Brazil. Revista Brasileira de Zootecnia, 40(8), 1837-1843.

Sodré, Geni S, Marchini, L. C., Carvalho, C. A. L., \& Moreti, A. C. (2007). Pollen analysis in honey samples from the two main producing regions in the Brazilian northeast. Anais da Academia Brasileira de Ciências, 79(3), 381-388.

Souza, C. M., Silva, S., Nascimento, A. S., Santos, P. C., \& Carvalho, C. A. L. (2020). Caracterização so "samburá" de abelhas sociais sem ferrão. In Atena Editora. Atena Editora. https://doi.org/10.22533/at.ed.8412003066

Souza, Carla Marques, Silva, S. M. P. C., Nascimento, A. S., Silva, F. L., Bagaldo, A. R., \& Carvalho, C. A. L. (2021). Chemical and microbiological characterization of "samburá" from two stingless bee species. Journal of Apicultural Research, 1-9. https://doi.org/10.1080/00218839.2021.1918408 
Vásquez, A., \& Olofsson, T. C. (2009). The lactic acid bacteria involved in the production of bee pollen and bee bread. Journal of Apicultural Research, 48(3), 189-195. https://doi.org/10.3896/IBRA.1.48.3.07.

Vit, P., Santiago, B., Silvia, P., Ruiz, J., Maza, F., Pena-Vera, M., \& Perez-Perez, E. (2016). Caracterização química e bioativa do pólen produzido por abelhas Melipona e Scaptotrigona sem ferrão de Paria Grande, Estado do Amazonas, Venezuela. Emirates Journal of Food and Agriculture, 28, 78-84.

\section{Histórico do artigo:}

Recebido: 2 de agosto de 2021

Aprovado: 18 de setembro de 2021

Disponível online: 11 de novembro de 2021
Licenciamento: Este artigo é publicado na modalidade Acesso Aberto sob a licença Creative Commons Atribuição 4.0 (CC-BY 4.0), a qual permite uso irrestrito, distribuição, reprodução em qualquer meio, desde que o autor e a fonte sejam devidamente creditados. 